\title{
Review Article \\ The Application of SELDI-TOF-MS in Clinical Diagnosis of Cancers
}

\author{
Chibo Liu \\ Department of Laboratory Medicine, The Affiliated Taizhou Municipal Hospital, Taizhou Medical College, \\ Taizhou 318000, Zhejiang Province, China \\ Correspondence should be addressed to Chibo Liu, chibo_liu@163.com
}

Received 20 December 2010; Accepted 30 March 2011

Academic Editor: Vincent C. O. Njar

Copyright ( 92011 Chibo Liu. This is an open access article distributed under the Creative Commons Attribution License, which permits unrestricted use, distribution, and reproduction in any medium, provided the original work is properly cited.

Cancer diagnosis is important, and the early diagnosis of cancers could predict a more successful treatment. The proteomic studies emerged to be useful in combined analyses of samples from patients and provide more accurate diagnosis when compared to the single-factor-based diagnosis. In recent years, cancer detection with surface-enhanced laser desorption/ionization time of flight mass spectrometry (SELDI-TOF MS) is flourishing and brought significant progress in this area. This paper summarizes some recent results with this technique for cancer diagnosis.

\section{Introduction}

Cancer diagnosis is important, and the early diagnosis of cancers could predict a more successful treatment. The accurate diagnosis of cancers before the appearance of symptoms often relies on the identification of reliable biomarkers. Further, these biomarkers reflecting the progression of cancers suggest the etiology of the disease. Proteomics technology has emerged to be important tools in cancer diagnosis and evaluation tools during treatment through the analyses of changes in cancer biomarkers. The fact that people have identified diverse biomarkers during the development and progression of different cancers suggested that the specificity and abundance of many small proteins could reflect the current state of cancer progression, and even predict the treatment efficacy. From serum, saliva, urine, and so forth, people could acquire the complete proteome that reflect the dynamic proteomics of the patients with high accuracy; and proteomic analyses permit the combined comparison of several biomarkers at the same time, which could finally bring convincing results. This included two-dimensional gel electrophoresis (2-DE), one-or two-dimensional liquid chromatographic (LC-MS), and surface-enhanced laser desorption/ionization time of flight mass spectrometry (SELDITOF MS). In the present paper we review the progresses achieved in using SELDI-TOF MS technology for cancer biomarker profiling and detection.

\section{Introduction to SELDI-TOF MS}

The SELDI-TOF MS technique was firstly introduced in 1993 [1] and was commercialized by Ciphergen Biosystems in 1997 as the ProteinChip system. SELDI-TOF-MS is one type of variation of matrix-assisted laser desorption/ionization (MALDI) that uses a target modified to reach biochemical affinity with the sample proteins. The differences between the two techniques are the following. In MALDI, the sample is mixed with the matrix molecule in solution, and a small amount of the mixture was deposited on a surface to dry. This made the sample and matrix cocrystallized after the solvent evaporated. On the other hand, in SELDI, the mixture is spotted on a surface modified with a chemical functionality such as binding affinity. Without being dried, some proteins in the samples would bind to the modified 
surface, while the others were washed off. Then the matrix is applied to the surface for crystallization with the sample peptides. In the binding and washing off steps the surfacebound proteins are left for analyses. Samples spotted on an SELDI surface were typically analyzed with time-of-flight mass spectrometry (TOF-MS) [2]. A laser-ionized peptides from crystals of the sample and matrix mixture. These ions were then accelerated through an electric field and down into the flight tube. Finally, the detector would measure ions as they reach the end of the tube (Figure 1). The mass-to-charge ratio of each ion could be determined from the length of the tube, the kinetic energy given to ions by the electric field, and the time taken to travel the length of the tube. Some surfaces that were normally adopted include CM10 (weak-positive ion exchange), H50 (hydrophobic surface, similar to C6-C12 reverse phase chromatography), IMAC30 (metal-binding surface), and Q10 (strong anion exchanger). Surfaces can also be modified or functionalized with antibodies, other proteins with proper binding properties, or even DNA.

\section{Body Fluids as Important SELDI-TOF MS Samples}

One of the key features of SELDI-TOF MS is the little requirement of sample purification or protein separations before the MS analyses. With high sensitivity to low-molecular-weight proteins (less than $15 \mathrm{kda}$ ), SELDI-TOF MS could detect some biomarkers that were neglected in other proteomic analyses such as 2D-gels [3, 4]. In finding samples for SELDITOF MS analysis, both tissue extracts and body fluids could be used. In past studies, the analyzed body fluids include plasma, serum, urine, saliva, amniotic fluid, cerebrospinal liquid, bronchoalveolar wash out, tears, and nipple aspirate fluid [5-23]. Among these choices, serum, urine, saliva, and plasma were most widely used.

The challenge that biomarker proteins only take a very small proportion in total plasma proteins-less than one percent suggested that MS is more suitable in cancer detection in compared to other less sensitive approaches [24]. Moreover, the levels of proteins could vary according to the environmental stress, codiseased disorders or previous drug treatments $[24,25]$. Sometimes, the proteins were modified or cleaved by enzymes, which further decreased the amount of biomarkers for detection in body fluids. All these difficulties suggested that cancer detection should adopt SELDI-TOF MS technique with high sensitivity and without the need of previous protein purification from samples. Consistently, it was showed that the highly abundant proteins in the serum such as albumin and immunoglobulin could be well separated from potential markers without causing any inference [16, 26-29].

\section{Cancer Diagnosis}

Many types of cancers could be and have been diagnosed with SELDI-TOF MS technology. It is possible to read the different peaks in samples from control and patients, as shown in Figure 2. In the paragraphs below, we selected

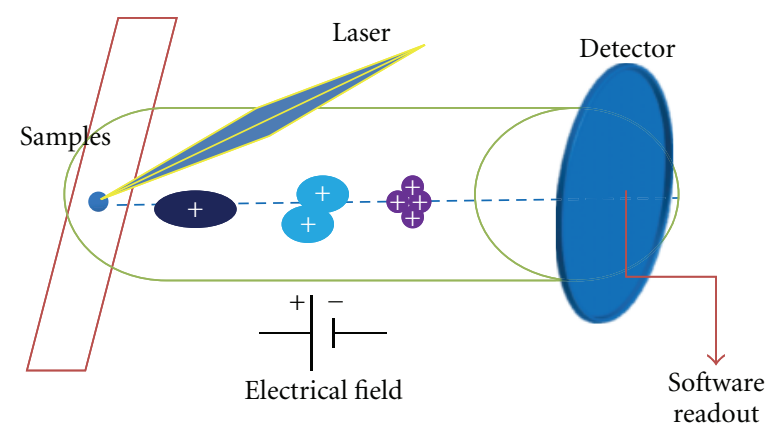

Figure 1: After the samples were dried, a laser-ionized peptides from crystals of the sample and matrix mixture. Then, these ions were accelerated through an external electric field and down into the flight tube. Finally, the detector would measure ions as they reach the end of the tube with software readout the data.

ovarian cancer, breast cancer, prostate cancer, and hepatocellular cancer as examples showing how the new technique promoted the diagnosis of these cancers.

4.1. Ovarian Cancer. It was found that early diagnosed (phase I) ovarian cancer patients have the 5-year survival rates more than $90 \%$, which is $35 \%$ in most middle-late phase cases [30, 31]. Some studies tried to diagnose phase I patients accurately. For instance, one study adopted C16 surface chips with SELDI-TOF MS in analyzing 50 patient cases and found a different pattern of proteome including five peaks at 534, 989, 21 11, 2251, and 2465, respectively, $[31,32]$. In most of these studies, the method could reach diagnosis accuracy, sensitivity, and specificity of more than $99 \%$, especially when combined with improved statistical methods [33-40]. Taken together, SELDI-TOF MS could be an important and very accurate tool in diagnosing ovarian cancer patients, both in early and advanced stages.

4.2. Breast Cancer. X-ray examination was now routinely adopted for women aged more than 40 years old however, the accuracy is only around 50\%. There were some available biomarkers in serum for breast cancer diagnosis, such as CA15.3, but with low sensitivity (23\%) and specificity (69\%) $[41,42]$. In one study that combined IMAC-Ni ${ }^{2+}$ chip with SELDI-TOF MS, the authors showed three protein spectrum peaks at $4.3,8.1$, and $8.92 \mathrm{kda}$, respectively, combined analyses with the three peaks in 169 cases (103 patient cases) and showed the diagnosis sensitivity $93 \%$ and specificity $96 \%$ [43]. In other studies, many other potential biomarkers have been identified, and reached high accuracy in diagnosis [44-55], and combined analyses of these biomarkers could further improve the sensitivity and specificity.

4.3. Prostate Cancer. Prostate-specific antigen (PSA) has been widely used in prostate cancer diagnosis with relatively high sensitivity but quite low specificity $[56,57] \quad 95 \%$ and $18 \%$, respectively, as shown in one previous study [58]. Many studies have adopted SELDI-TOF MS to find better biomarker for early prostate cancer diagnosis [59-68]. One 


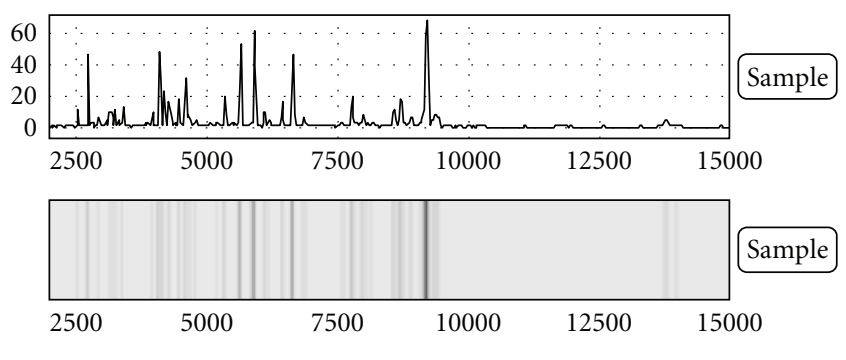

(a)
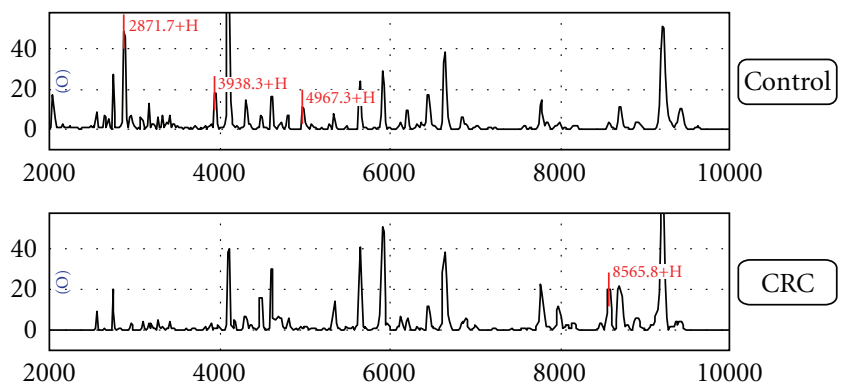

(b)

Figure 2: Samples from control and colorectal cancer patients showed different peaks in proteomics spectrum. Some changes were highlighted.

study compared serum samples from prostate cancer patients and patients with other prostate diseases for SELDI-TOF MS analyses; they found several biomarkers including PC1, PC2, and PC3, with higher sensitivity when compared to PSAbased diagnosis in the study involved in more than 300 cases [69]. The serum-based proteomic analysis would become one of the major diagnosis tools for prostate cancer in the future.

4.4. Hepatocellular Cancer. Hepatocellular cancer (HCC) is the most common primary malignant tumor of the liver. Primary liver cancer accounts for less than $1 \%$ of all cancers in states, however, in past decades, this increased due to a large pool of people with longstanding hepatitis $\mathrm{C}$ virus infection. This is even worse in China and many developing countries. The detection of HCC could be very difficult, as most patients onset without any symptoms. Ultrasound detection and alpha-fetoprotein (AFP) in the serum were used in past studies $[71,72]$. However, it should be noted that serum AFP levels were normal in $40 \%$ patients with $<2 \mathrm{~cm}$ (in diameter) hepatocellular carcinoma and in $28 \%$ of those with tumors 2 to $5 \mathrm{~cm}$ in diameter. Additionally, not all hepatocellular carcinomas secrete AFP such as the Fibrolamellar type. The AFP levels could also be elevated in pregnancy, other gonadal originated tumors, and even in acute or chronic liver diseases (CLD) without tumor. All of these weakened the sensitivity and specificity of AFP as serum biomarkers for HCC.

SELDI-TOF MS have been adopted to find new biomarkers for HCC diagnosis [71, 73-82]. In another study, the authors adopted the multidimensional separated statistics in analyzing the proteomics data and showed diagnosis
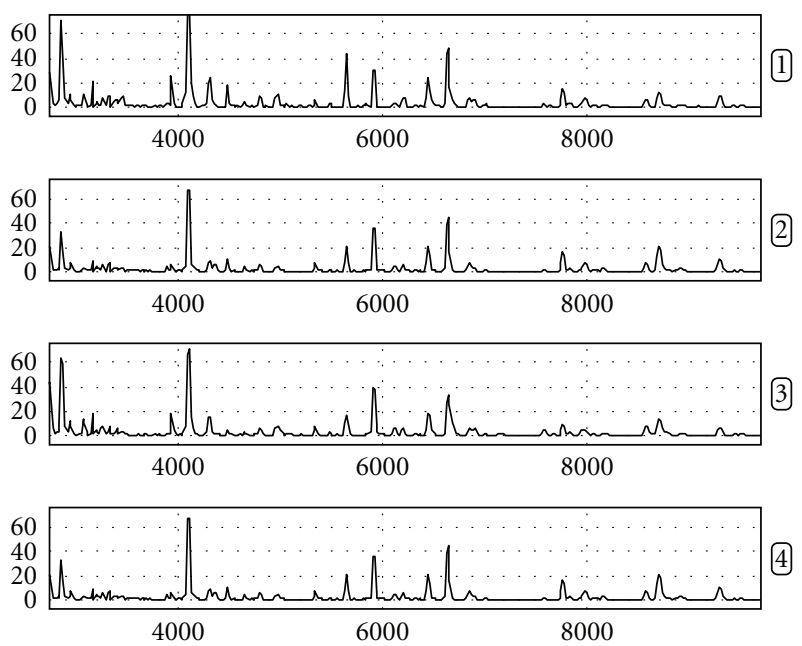

FIGURE 3: This represented the reproducibility of four separate analyses from the healthy controls of blood type $\mathrm{O}$, suggesting the high reliability of SELDI-TOF MS in serum sample analyses [70].

specificity of $90 \%$ and sensitivity of $92 \%$ in separating HCC out of CLD, which could not be reached with AFP examination [83]. More interestingly, their works showed the proteomics between subtypes of HCC: the progressive one and the metastasis one. All these data could provide new hopes for accurate and early detection of HCC in patients or people living in areas with hepatitis $B$ and $C$ virus infection.

It should be noted that in practice, the combined use of several potential biomarkers could greatly increase the specificity and sensitivity of cancer diagnosis $[46,84-88]$. It is now convenient to set up the diagnostic tree with software, and the diagnosis automatically follows. These selected combinations could be considered as a group of biomarkers representing the etiology of cancer in given population, which might provide some rationale bases for therapeutic developments.

\section{Summary}

In this paper, we briefly summarized the recent progresses achieved in cancer detection and diagnosis with SELDI-TOF MS technique. The use of body fluids and tissue extracts with low proteins content as samples in this technology is superior to many other available proteomic approaches. Moreover, SELDI-TOF MS is very sensitive and reliable in repeated tests (Figure 3) [70]. It should also be noted that SELDI-TOFMS could also contribute to the ongoing human proteome studies, as proposed for the total proteins in the serum $[2,29,89]$. When combined with radiological data, this could finally bring patients new hopes in the early detection of the tumors inside even before the onset of symptoms. For instance, the detection of specific changes in one protein might point out the potential regions of cancer genesis and, therefore, suggest the regions of interest for radiologist; also, when unknown tissues were identified in the radiological report, the accurate SELDI-TOF-MS could be used to verify the existence of a tumor. We believe that SELDI-TOF-MS 
would become one of the most powerful tools in early cancer diagnosis in coming days.

\section{Acknowledgments}

The work was funded by Zhejiang Medicine, Health, and Science Grant no. 2010KYB127, Educational Commission of Zhejiang Province Grant no. Y201016269, Science and Technology Planning Project of Hangzhou 20100633B13, and Zhejiang Gong Yi Xing Technology Application Project Grant no. 2011C33SA810001. The author also thanks the Department of Laboratory Medicine, the Affiliated Taizhou Municipal Hospital and Taizhou Medical College for supports.

\section{References}

[1] T. W. Hutchens and T. T. Yip, "New desorption strategies for the mass spectrometric analysis of macromolecules," Rapid Commun Mass Spectrom, vol. 7, pp. 576-580, 1993.

[2] M. Zhou and T. D. Veenstra, "Mass spectrometry: m/z 19832008," BioTechniques, vol. 44, no. 5, pp. 667-670, 2008.

[3] N. Tang, P. Tornatore, and S. R. Weinberger, "Current developments in SELDI affinity technology," Mass Spectrometry Reviews, vol. 23, no. 1, pp. 34-44, 2004.

[4] G. L. Wright, "SELDI proteinchip MS: a platform for biomarker discovery and cancer diagnosis," Expert Review of Molecular Diagnostics, vol. 2, no. 6, pp. 549-563, 2002.

[5] M. Abramovitz and B. Leyland-Jones, "A systems approach to clinical oncology: focus on breast cancer," Proteome Science, vol. 4, Article ID 5, 2006.

[6] A. M. Ardekani, L. A. Liotta, and E. F. Petricoin, "Clinical potential of proteomics in the diagnosis of ovarian cancer," Expert Review of Molecular Diagnostics, vol. 2, no. 4, pp. 312320, 2002.

[7] F. Bertucci, D. Birnbaum, and A. Goncalves, "Proteomics of breast cancer: principles and potential clinical applications," Molecular and Cellular Proteomics, vol. 5, no. 10, pp. 17721786, 2006.

[8] P. Chaurand, S. A. Schwartz, and R. M. Caprioli, "Assessing protein patterns in disease using imaging mass spectrometry," Journal of Proteome Research, vol. 3, no. 2, pp. 245-252, 2004.

[9] P. Chaurand, S. A. Schwartz, M. L. Reyzer, and R. M. Caprioli, "Imaging mass spectrometry: principles and potentials," Toxicologic Pathology, vol. 33, no. 1, pp. 92-101, 2005.

[10] S. Ciordia, V. de los Ríos, and J. P. Albar, "Contributions of advanced proteomics technologies to cancer diagnosis," Clinical and Translational Oncology, vol. 8, no. 8, pp. 566-580, 2006.

[11] V. Combaret, C. Bergeron, S. Bréjon et al., "Protein chip array profiling analysis of sera from neuroblastoma patients," Cancer Letters, vol. 228, no. 1-2, pp. 91-96, 2005.

[12] P. Del Boccio and A. Urbani, "Homo sapiens proteomics: clinical perspectives," Annali dell'Istituto Superiore di Sanita, vol. 41, no. 4, pp. 479-482, 2005.

[13] R. R. Drake, K. Y. White, T. W. Fuller et al., "Clinical collection and protein properties of expressed prostatic secretions as a source for biomarkers of prostatic disease," Journal of Proteomics, vol. 72, no. 6, pp. 907-917, 2009.

[14] N. A. Henderson and R. J. C. Steele, "SELDI-TOF proteomic analysis and cancer detection," Surgeon, vol. 3, no. 6, pp. 383390, 2005.
[15] K. D. Herring, S. R. Oppenheimer, and R. M. Caprioli, "Direct tissue analysis by matrix-assisted laser desorption ionization mass spectrometry: application to kidney biology," Seminars in Nephrology, vol. 27, no. 6, pp. 597-608, 2007.

[16] M. A. Karpova, S. A. Moshkovskii, I. Y. Toropygin, and A. I. Archakov, "Cancer-specific MALDI-TOF profiles of blood serum and plasma: biological meaning and perspectives," Journal of Proteomics, vol. 73, no. 3, pp. 537-551, 2010.

[17] J. E. Katz, P. Mallick, and D. B. Agus, "A perspective on protein profiling of blood," BJU International, vol. 96, no. 4, pp. 477482, 2005.

[18] D. B. Martin and P. S. Nelson, "From genomics to proteomics: techniques and applications in cancer research," Trends in Cell Biology, vol. 11, no. 11, pp. S60-S65, 2001.

[19] P. P. Massion and R. M. Caprioli, "Proteomic strategies for the characterization and the early detection of lung cancer," Journal of Thoracic Oncology, vol. 1, no. 9, pp. 1027-1039, 2006.

[20] D. E. Misek, T. H. Patwa, D. M. Lubman, and D. M. Simeone, "Early detection and biomarkers in pancreatic cancer," Journal of the National Comprehensive Cancer Network, vol. 5, no. 10, pp. 1034-1041, 2007.

[21] H. Shau, G. S. Chandler, J. P. Whitelegge, J. A. Gornbein, K. F. Faull, and H. R. Chang, "Proteomic profiling of cancer biomarkers," Brief Funct Genomic Proteomic, vol. 2, no. 2, pp. 147-158, 2003.

[22] J. D. Wulfkuhle, C. P. Paweletz, P. S. Steeg, E. F. Petricoin, and L. Liotta, "Proteomic approaches to the diagnosis, treatment, and monitoring of cancer," Advances in Experimental Medicine and Biology, vol. 532, pp. 59-68, 2003.

[23] Z. Xiao, D. Prieto, T. P. Conrads, T. D. Veenstra, and H. J. Issaq, "Proteomic patterns: their potential for disease diagnosis," Molecular and Cellular Endocrinology, vol. 230, no. 1-2, pp. 95106, 2005.

[24] N. L. Anderson and N. G. Anderson, "The human plasma proteome: history, character, and diagnostic prospects," Molecular \& Cellular Proteomics, vol. 1, no. 11, pp. 845-867, 2002.

[25] V. Seibert, M. P. A. Ebert, and T. Buschmann, "Advances in clinical cancer proteomics: SELDI-ToF-mass spectrometry and biomarker discovery," Briefings in Functional Genomics and Proteomics, vol. 4, no. 1, pp. 16-26, 2005.

[26] A. Fink-Retter, K. Czerwenka, D. Gschwantler-Kaulich et al., "Proteomics in mammary cancer research," European Journal of Gynaecological Oncology, vol. 30, no. 6, pp. 635-639, 2009.

[27] V. M. Garrisi, I. Abbate, M. Quaranta, A. Mangia, S. Tommasi, and A. Paradiso, "SELDI-TOF serum proteomics and breast cancer: which perspective?" Expert Review of Proteomics, vol. 5, no. 6, pp. 779-785, 2008.

[28] K. Somasundaram, M. B. Nijaguna, and D. M. Kumar, "Serum proteomics of glioma: methods and applications," Expert Review of Molecular Diagnostics, vol. 9, no. 7, pp. 695-707, 2009.

[29] L. C. Whelan, K. A. R. Power, D. T. McDowell, J. Kennedy, and W. M. Gallagher, "Applications of SELDI-MS technology in oncology," Journal of Cellular and Molecular Medicine, vol. 12, no. 5, pp. 1535-1547, 2008.

[30] C. Y. Lin, K. H. Tsui, C. C. Yu, C. W. Yeh, P. L. Chang, and B. Y. M. Yung, "Searching cell-secreted proteomes for potential urinary bladder tumor markers," Proteomics, vol. 6, no. 15, pp. 4381-4389, 2006.

[31] E. F. Petricoin, A. M. Ardekani, B. A. Hitt et al., "Use of proteomic patterns in serum to identify ovarian cancer," Lancet, vol. 359, no. 9306, pp. 572-577, 2002. 
[32] E. F. Petricoin and L. A. Liotta, "Mass spectrometry-based diagnostics: the upcoming revolution in disease detection," Clinical Chemistry, vol. 49, no. 4, pp. 533-534, 2003.

[33] I. Cadron, T. Van Gorp, F. Amant et al., "The use of laser microdissection and SELDI-TOF MS in ovarian cancer tissue to identify protein profiles," Anticancer Research, vol. 29, no. 4, pp. 1039-1046, 2009.

[34] G. S. Leiserowitz, C. Lebrilla, S. Miyamoto et al., "Glycomics analysis of serum: a potential new biomarker for ovarian cancer?" International Journal of Gynecological Cancer, vol. 18, no. 3, pp. 470-475, 2008.

[35] K. L. Tang, T. H. Li, W. W. Xiong, and K. Chen, "Ovarian cancer classification based on dimensionality reduction for SELDI-TOF data," BMC Bioinformatics, vol. 11, Article ID 109, 2010.

[36] J. Wang, X. Zhang, X. Ge, H. Guo, G. Xiong, and Y. Zhu, "Proteomic studies of early-stage and advanced ovarian cancer patients," Gynecologic Oncology, vol. 111, no. 1, pp. 111-119, 2008.

[37] S. P. Wu, Y. W. Lin, H. C. Lai, T. Y. Chu, YU. L. Kuo, and H. S. Liu, "SELDI-TOF MS profiling of plasma proteins in ovarian cancer," Taiwanese Journal of Obstetrics and Gynecology, vol. 45, no. 1, pp. 26-32, 2006.

[38] J. S. Yu, S. Ongarello, R. Fiedler et al., "Ovarian cancer identification based on dimensionality reduction for highthroughput mass spectrometry data," Bioinformatics, vol. 21, no. 10, pp. 2200-2209, 2005.

[39] H. Zhang, B. Kong, X. Qu, L. Jia, B. Deng, and Q. Yang, "Biomarker discovery for ovarian cancer using SELDI-TOFMS," Gynecologic Oncology, vol. 102, no. 1, pp. 61-66, 2006.

[40] Y. Zhu, R. Wu, N. Sangha et al., "Classifications of ovarian cancer tissues by proteomic patterns," Proteomics, vol. 6, no. 21, pp. 5846-5856, 2006.

[41] F. Lumachi and S. M. M. Basso, "Serum tumor markers in patients with breast cancer," Expert Review of Anticancer Therapy, vol. 4, no. 5, pp. 921-931, 2004.

[42] F. Safi, I. Kohler, E. Rottinger, and H. G. Beger, "The value of the tumor marker CA 15-3 in diagnosing and monitoring breast cancer: a comparative study with carcinoembryonic antigen," Cancer, vol. 68, no. 3, pp. 574-582, 1991.

[43] J. Li, Z. Zhang, J. Rosenzweig, Y. Y. Wang, and D. W. Chan, "Proteomics and bioinformatics approaches for identification of serum biomarkers to detect breast cancer," Clinical Chemistry, vol. 48, no. 8, pp. 1296-1304, 2002.

[44] J. E. Celis, P. Gromov, T. Cabezón et al., "Proteomic characterization of the interstitial fluid perfusing the breast tumor microenvironment," Molecular and Cellular Proteomics, vol. 3, no. 4, pp. 327-344, 2004.

[45] G. F. Davies, A. R. Ross, T. G. Arnason, B. H. J. Juurlink, and T. A. A. Harkness, "Troglitazone inhibits histone deacetylase activity in breast cancer cells," Cancer Letters, vol. 288, no. 2, pp. 236-250, 2010.

[46] Y. Fan, J. Wang, Y. Yang et al., "Detection and identification of potential biomarkers of breast cancer," Journal of Cancer Research and Clinical Oncology, vol. 136, pp. 1243-1254, 2010.

[47] M. C. W. Gast, C. H. van Gils, L. F. A. Wessels et al., "Serum protein profiling for diagnosis of breast cancer using SELDITOF MS," Oncology Reports, vol. 22, no. 1, pp. 205-213, 2009.

[48] Q. He, S. Q. Zhang, Y. L. Chu, X. L. Jia, L. H. Zhao, and X. L. Wang, "Separation and identification of differentially expressed nuclear matrix proteins in breast carcinoma forming," Acta Oncologica, vol. 49, no. 1, pp. 76-84, 2010.

[49] V. C. Hodgkinson, G. L. Eagle, P. J. Drew, M. J. Lind, and L. Cawkwell, "Biomarkers of chemotherapy resistance in breast cancer identified by proteomics: current status," Cancer Letters, vol. 294, no. 1, pp. 13-24, 2010.

[50] L. Chouchane, M. Kabbage, K. Chahed et al., "Protein alterations in infiltrating ductal carcinomas of the breast as detected by nonequilibrium $\mathrm{pH}$ gradient electrophoresis and mass spectrometry," Journal of Biomedicine and Biotechnology, vol. 2008, no. 1, Article ID 564127, 2008.

[51] T. C. Lai, H. C. Chou, Y. W. Chen et al., "Secretomic and proteomic analysis of potential breast cancer markers by two-dimensional differential gel electrophoresis," Journal of Proteome Research, vol. 9, no. 3, pp. 1302-1322, 2010.

[52] E. Lattová, B. Tomanek, D. Bartusik, and H. Perreault, "NGlycomic changes in human breast carcinoma MCF-7 and T-lymphoblastoid cells after treatment with Herceptin and Herceptin/Lipoplex," Journal of Proteome Research, vol. 9, no. 3, pp. 1533-1540, 2010.

[53] S. Rauser, C. Marquardt, B. Balluff et al., "Classification of HER2 receptor status in breast cancer tissues by MALDI imaging mass spectrometry," Journal of Proteome Research, vol. 9, no. 4, pp. 1854-1863, 2010.

[54] B. A. Zeidan, R. I. Cutress, N. Murray et al., "Proteomic analysis of archival breast cancer serum," Cancer Genomics and Proteomics, vol. 6, no. 3, pp. 141-148, 2009.

[55] B. A. Zeidan and P. A. Townsend, "SELDI-TOF proteomic profiling of breast carcinomas identifies clinicopathologically relevant groups of patients similar to previously defined clusters from cDNA expression," Breast Cancer Research, vol. 10, no. 3, p. 107, 2008.

[56] P. De Visschere, W. Oosterlinck, G. De Meerleer, and G. Villeirs, "Clinical and imaging tools in the early diagnosis of prostate cancer, a review," JBR-BTR, vol. 93, no. 2, pp. 62-70, 2010.

[57] P. A. Humphrey and G. L. Andriole, "Prostate cancer diagnosis," Missouri Medicine, vol. 107, no. 2, pp. 107-112, 2010.

[58] A. W. Roddam, M. J. Duffy, F. C. Hamdy et al., "Use of prostate-specific antigen (PSA) isoforms for the detection of prostate cancer in men with a PSA level of $2-10 \mathrm{ng} / \mathrm{ml}$ : systematic review and meta-analysis," European Urology, vol. 48, no. 3, pp. 386-399, 2005.

[59] C. D. Calvano, A. Aresta, M. Iacovone et al., "Optimization of analytical and pre-analytical conditions for MALDI-TOF-MS human urine protein profiles," Journal of Pharmaceutical and Biomedical Analysis, vol. 51, no. 4, pp. 907-914, 2010.

[60] M. Gross, I. Top, I. Laux et al., " $\beta$-2-microglobulin is an androgen-regulated secreted protein elevated in serum of patients with advanced prostate cancer," Clinical Cancer Research, vol. 13, no. 7, pp. 1979-1986, 2007.

[61] M. Kohli, E. Siegel, S. Bhattacharya, M. A. Khan, R. Shah, and L. J. Suva, "Surface-enhanced laser desorption/ionization time-of-flight mass spectrometry (SELDI-TOF MS) for determining prognosis in advanced stage hormone relapsing prostate cancer," Cancer Biomarkers, vol. 2, no. 6, pp. 249-258, 2006.

[62] Z. Kyselova, Y. Mechref, M. M. Al Bataineh et al., "Alterations in the serum glycome due to metastatic prostate cancer," Journal of Proteome Research, vol. 6, no. 5, pp. 1822-1832, 2007.

[63] H. Lexander, C. Palmberg, U. Hellman et al., "Correlation of protein expression, Gleason score and DNA ploidy in prostate cancer," Proteomics, vol. 6, no. 15, pp. 4370-4380, 2006.

[64] J. A. Mobley, Y. W. Lam, K. M. Lau et al., "Monitoring the serological proteome: the latest modality in prostate cancer detection.," The Journal of Urology, vol. 172, no. 1, pp. 331337,2004 . 
[65] I. Rehman, A. R. Azzouzi, J. W. F. Catto et al., "Proteomic analysis of voided urine after prostatic massage from patients with prostate cancer: a pilot study," Urology, vol. 64, no. 6, pp. 1238-1243, 2004.

[66] A. Skytt, E. Thysell, P. Stattin, U. H. Stenman, H. Antti, and P. Wikström, "SELDI-TOF MS versus prostate specific antigen analysis of prospective plasma samples in a nested case-control study of prostate cancer," International Journal of Cancer, vol. 121, no. 3, pp. 615-620, 2007.

[67] S. J. Yoon, S. Y. Park, P. C. Pang et al., "N-glycosylation status of $\beta$-haptoglobin in sera of patients with prostate cancer vs. benign prostate diseases," International Journal of Oncology, vol. 36, no. 1, pp. 193-203, 2010.

[68] M. Zhou, D. A. Prieto, D. A. Lucas et al., "Identification of the SELDI ProteinChip human serum retentate by microcapillary liquid chromatography-tandem mass spectrometry," Journal of Proteome Research, vol. 5, no. 9, pp. 2207-2216, 2006.

[69] J. Li, N. White, Z. Zhang et al., "Detection of prostate cancer using serum proteomics pattern in a histologically confirmed population," Journal of Urology, vol. 171, no. 5, pp. 1782-1787, 2004.

[70] R. Guo, C. Pan, J. Shen, and C. Liu, "New serum biomarkers for detection of esophageal carcinoma using Matrix-assisted laser desorption/ionization time-of-flight mass spectrometry," Journal of Cancer Research and Clinical Oncology, vol. 137, pp. 513-519, 2011.

[71] N. P. Lee, L. Chen, M. C. Lin et al., "Proteomic expression signature distinguishes cancerous and nonmalignant tissues in hepatocellular carcinoma," Journal of Proteome Research, vol. 8, no. 3, pp. 1293-1303, 2009.

[72] N. T. Zinkin, F. Grall, K. Bhaskar et al., "Serum proteomics and biomarkers in hepatocellular carcinoma and chronic liver disease," Clinical Cancer Research, vol. 14, no. 2, pp. 470-477, 2008.

[73] G. Corona, E. De Lorenzo, C. Elia et al., "Differential proteomic analysis of hepatocellular carcinoma," International Journal of Oncology, vol. 36, no. 1, pp. 93-99, 2010.

[74] J. F. Cui, Y. K. Liu, H. J. Zhou et al., "Screening serum hepatocellular carcinoma-associated proteins by SELDI-based protein spectrum analysis," World Journal of Gastroenterology, vol. 14, no. 8, pp. 1257-1262, 2008.

[75] X. Geng, F. Wang, Y. G. Li, G. P. Zhu, and W. M. Zhang, "SELDI-TOF MS proteinchip technology for screening of serum markers of HBV-induced hepatocellular carcinoma," Journal of Experimental and Clinical Cancer Research, vol. 26, no. 4, pp. 505-508, 2007.

[76] R. Goldman, H. W. Ressom, R. S. Varghese et al., "Detection of hepatocellular carcinoma using glycomic analysis," Clinical Cancer Research, vol. 15, no. 5, pp. 1808-1813, 2009.

[77] A. Kakehashi, A. Kato, M. Inoue et al., "Cytokeratin 8/18 as a new marker of mouse liver preneoplastic lesions," Toxicology and Applied Pharmacology, vol. 242, no. 1, pp. 47-55, 2010.

[78] E. Lattová, E. J. Mckenzie, M. L. H. Gruwel, V. Spicer, R. Goldman, and H. Perreault, "Mass spectrometric study of Nglycans from serum of woodchucks with liver cancer," Rapid Communications in Mass Spectrometry, vol. 23, no. 18, pp. 2983-2995, 2009.

[79] N. Li, Y. Long, X. Fan et al., "Proteomic analysis of differentially expressed proteins in hepatitis B virus-related hepatocellular carcinoma tissues," Journal of Experimental and Clinical Cancer Research, vol. 28, no. 1, Article ID 122, 2009.

[80] J. M. Matos, F. A. Witzmann, O. W. Cummings, and C. M. Schmidt, "A pilot study of proteomic profiles of human hepatocellular carcinoma in the United States," Journal of Surgical Research, vol. 155, no. 2, pp. 237-243, 2009.

[81] Y. Saito, N. Oba, S. Nishinakagawa et al., "Identification of B2-microgloblin as a candidate for early diagnosis of imaging-invisible hepatocellular carcinoma in patient with liver cirrhosis," Oncology Reports, vol. 23, no. 5, pp. 1325-1330, 2010.

[82] Z. Tang, R. S. Varghese, S. Bekesova et al., "Identification of N-glycan serum markers associated with hepatocellular carcinoma from mass spectrometry data," Journal of Proteome Research, vol. 9, no. 1, pp. 104-112, 2010.

[83] T. C. W. Poon, T. T. Yip, A. T. C. Chan et al., "Comprehensive proteomic profiling identifies serum proteomic signatures for detection of hepatocellular carcinoma and its subtypes," Clinical Chemistry, vol. 49, no. 5, pp. 752-760, 2003.

[84] C. Liu, H. Wang, C. Pan, S. Mou, and Y. Liang, "Serum protein fingerprint of patients with gastric cancer by SELDI technology," African Journal of Biotechnology, vol. 9, no. 15, pp. 2298-2304, 2010.

[85] J. Liu, Y. Guo, S. Fu, M. Yang, K. L. Sun, and W. N. Fu, "Hypomethylation-induced expression of S100A4 increases the invasiveness of laryngeal squamous cell carcinoma," Oncology Reports, vol. 23, no. 4, pp. 1101-1107, 2010.

[86] L. H. Liu, B. E. Shan, ZI. Q. Tian et al., "Potential biomarkers for esophageal carcinoma detected by matrix-assisted laser desorption/ionization time-of-flight mass spectrometry," Clinical Chemistry and Laboratory Medicine, vol. 48, no. 6, pp. 855-861, 2010.

[87] M. Liu, C. F. Li, H. S. Chen et al., "Differential expression of proteomics models of colorectal cancer, colorectal benign disease and healthy controls," Proteome Science, vol. 8, Article ID 16, 2010.

[88] W. Liu, X. Gao, Q. Cai et al., "Identification of novel serum biomarkers for gastric cancer by magnetic bead," Frontiers in Bioscience, vol. 2, pp. 961-971, 2010.

[89] A. Klein, "Human total serum N-glycome," Advances in Clinical Chemistry, vol. 46, pp. 51-85, 2008. 


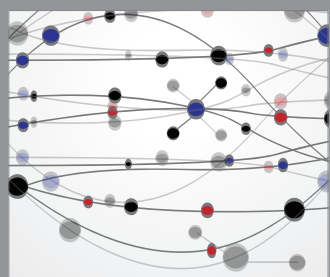

The Scientific World Journal
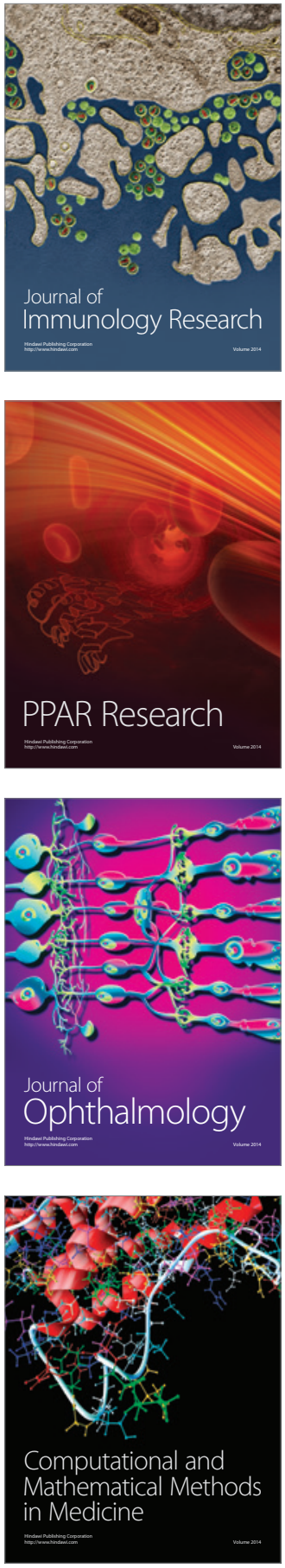

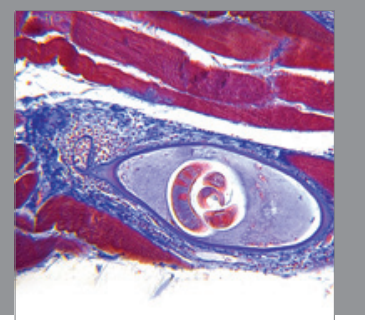

Gastroenterology

Research and Practice
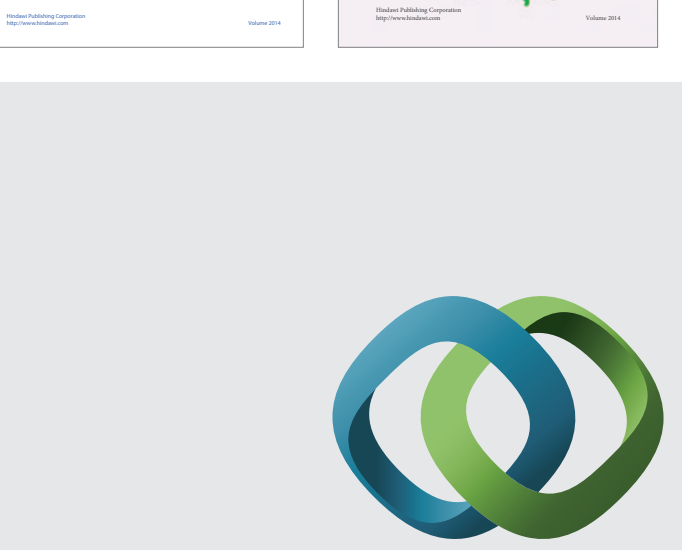

\section{Hindawi}

Submit your manuscripts at

http://www.hindawi.com
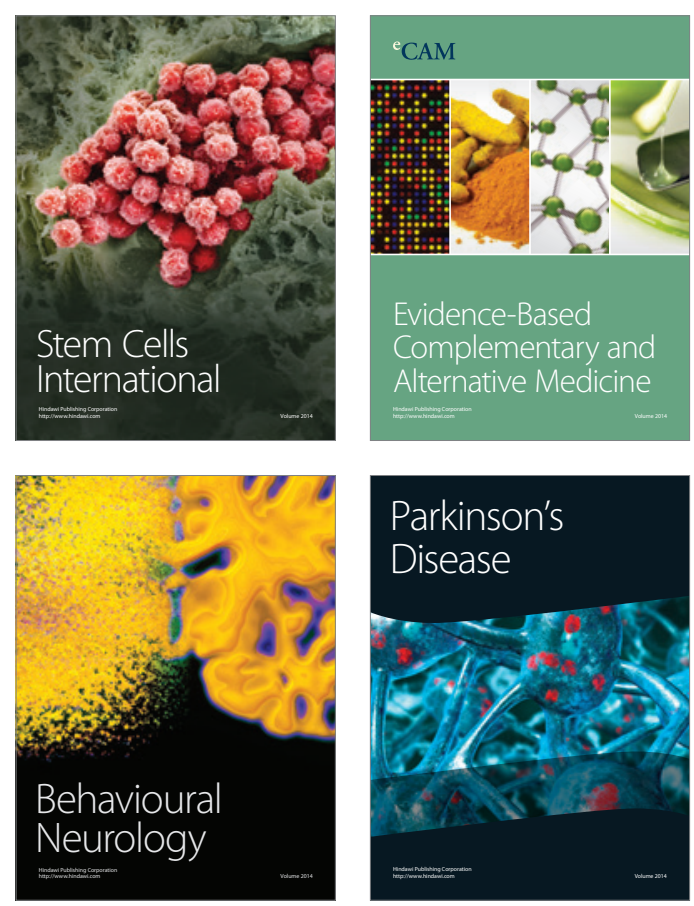

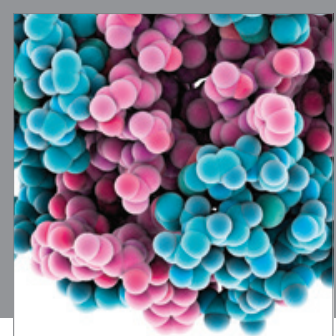

Journal of
Diabetes Research

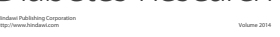

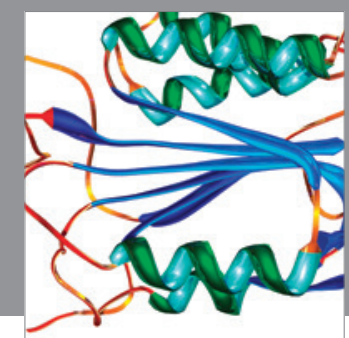

Disease Markers
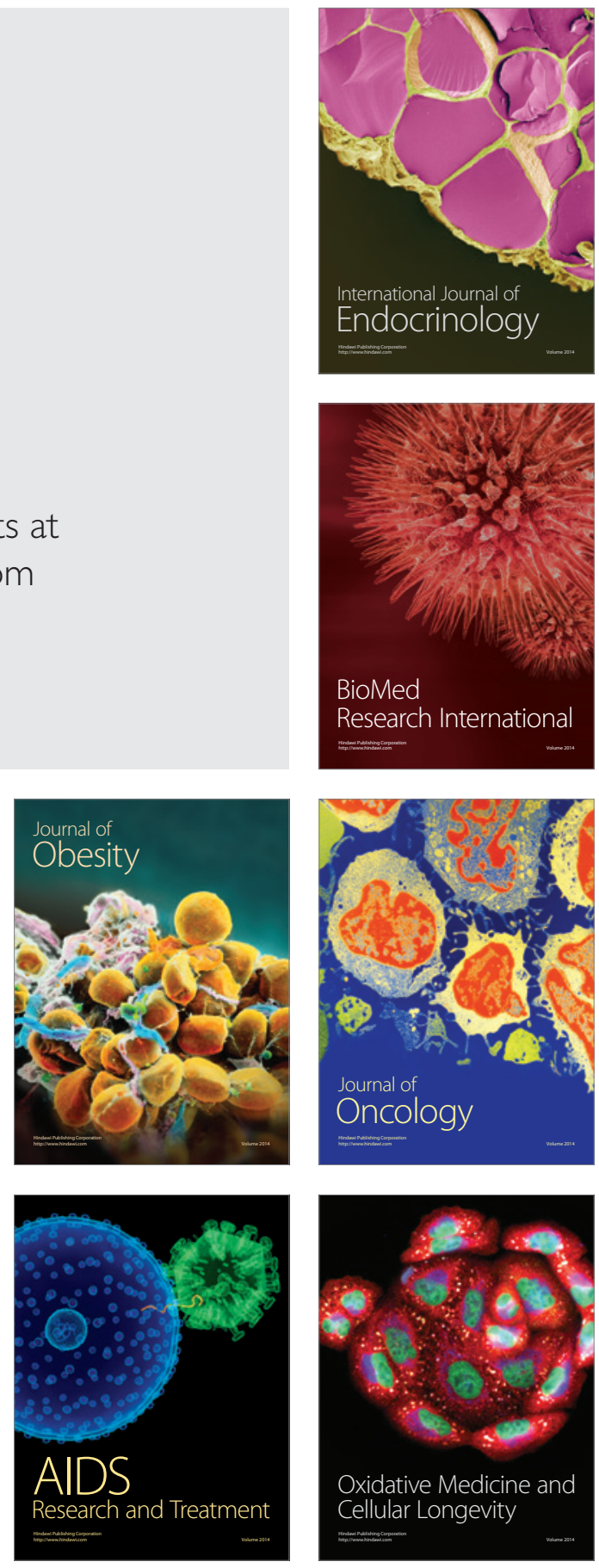